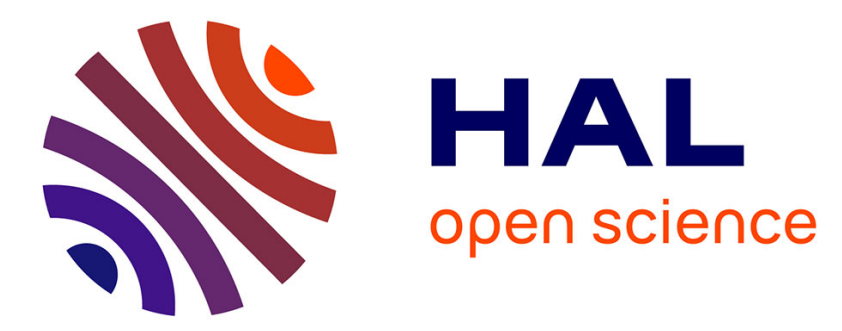

\title{
Simulation of Reconfigurable Assembly Cells with Unity3D
}

Magdalena Paul, Daria Leiber, Julian Pleli, Gunther Reinhart

\section{To cite this version:}

Magdalena Paul, Daria Leiber, Julian Pleli, Gunther Reinhart. Simulation of Reconfigurable Assembly Cells with Unity3D. IFIP International Conference on Advances in Production Management Systems (APMS), Sep 2019, Austin, TX, United States. pp.223-230, 10.1007/978-3-030-30000-5_29 . hal02419233

\section{HAL Id: hal-02419233 \\ https://hal.inria.fr/hal-02419233}

Submitted on 19 Dec 2019

HAL is a multi-disciplinary open access archive for the deposit and dissemination of scientific research documents, whether they are published or not. The documents may come from teaching and research institutions in France or abroad, or from public or private research centers.
L'archive ouverte pluridisciplinaire HAL, est destinée au dépôt et à la diffusion de documents scientifiques de niveau recherche, publiés ou non, émanant des établissements d'enseignement et de recherche français ou étrangers, des laboratoires publics ou privés. 


\title{
Simulation of Reconfigurable Assembly Cells with Unity3D
}

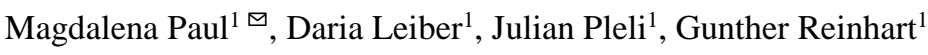 \\ ${ }^{1}$ Institute for Machine Tools and Industrial Management, Technical University of Munich, \\ Boltzmannstrasse 15, 85748 Garching, Germany

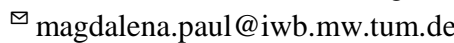

\begin{abstract}
This paper introduces a Unity3D-based simulation of reconfigurable assembly cells. A systematic approach defining flexibility ranges and comparing product requirements and cell capabilities allows the automated proposal of reconfigurations in the assembly cell. With this approach, the suitability of an existing cell can be examined for different variants of products while taking reconfiguration aspects into account. The simulation simplifies the process of introducing a new product to an assembly line. Through the virtual approach, designing of the product and line planning can be executed simultaneously, thereby decreasing cost and time-to-market for new variants in an existing production system.
\end{abstract}

Keywords: Simulation, Reconfigurability, Assembly, Unity3D.

\section{Introduction}

With the dynamization of product life cycles and the increasing number of variants, manufacturing companies are facing new challenges. The trend towards individualized mass production leads to the need of frequent modifications in the assembly system. Manufacturers need to adjust to the increasing number of variants using flexible and reconfigurable systems. [1] Flexibility describes the ability of a production system to adapt quickly and cost-effectively to changing influencing factors. Reconfigurability focuses on special manufacturing facilities that combine the advantages of highly specialized and adaptable systems. [2] Autonomous and standardized functional units allow for new machine configurations [3].

To be economically successful, reconfigurable production systems alone are not sufficient. The necessary changes also need to be identified, planned and implemented with reasonable effort [2]. In view of this, digital tools like simulation are of great importance. Through a simulative examination, the suitability of existing assembly cells for new products or variants can already be determined in early development phases. By detecting possible problems at an early stage, effort for redundant planning can be reduced [4]. The use of simulation tools thus contributes to exploiting the potential of 
reconfigurable assembly cells. In this paper, we present Unity3D as a software for the simulation of reconfigurable assembly cells.

\section{State of the Art}

\subsection{Simulation of Reconfigurable Assembly Cells}

Simulations can support the planning process of reconfigurable assembly cells in different ways. Gyulai et al. [5] develop a two-level, simulation-based approach, making the model capable of evaluating production plans and analyzing the emulation of the cell control. Their model is able to support the management of a modular cell and is proposing a possibility to decrease the commissioning time of new cells. A framework for the modelling of reconfigurable manufacturing systems by using hybridized discrete event and agent-based simulation is provided by Khedri et al. [6]. With the simulation, the authors provide insights on the emergent behavior of the agents of an intelligent manufacturing system. Further, Deif and ElMaraghy [7] use simulation augmented with Design of Experiment to analyze the performance of a reconfigurable manufacturing system with scalable capacity. Multiple performance measures lead them to propose a hybrid capacity scaling and marketing policy.

\subsection{Introduction of Unity3D}

Though Unity3D was primarily developed as a game engine, it offers a variety of advantages for the simulation of manufacturing systems. It is highly customizable and by using the integrated $\mathrm{C \# -code-base} \mathrm{and} \mathrm{physics} \mathrm{engine} \mathrm{various} \mathrm{assembly} \mathrm{line} \mathrm{behaviors}$ can be simulated. The simulation can consider mass, drag, springiness, bounciness and collision of objects. Furthermore, simulations generated with Unity3D can be easily used for demonstration purposes. They can be released on virtual reality, augmented reality and as program- and browser-exports [8]. Not being bound to a specific medium, the display of the simulation can be ensured across different systems and locations. Being used as the games engine for half of the games worldwide, Unity3D provides an extensive documentation and tool library for the user. [9]

\subsection{Unity3D as a Simulation Tool}

Through a systematic literature review, previous work concerning Unity3D as a simulation tool has been identified. On the level of factory and systems, Sun et al. [10] propose a method to design a production line based in a multi-channel controller. Gaisbauer et al. [11] introduce a concept to integrate arbitrary motion simulations in common frameworks with standardized motion model units. Um et al. [12] use a Unity3D-based simulation to develop a concept if a modular factory which makes it possible to reconfigure individual machine stations without extensive engineering effort. Furthermore, the possibility of Unity3D to be used in virtual reality applications is 
examined for designing a lean manufacturing environment [13] and to develop interactive practice systems $[14,15]$. On the level of cells and stations, Koechling et al. [16] present a procedure to enable production planners to virtually inspect the production including the material flow before the actual implementation. No publications have been found covering the topic of reconfigurability in manufacturing systems connected to Unity3D.

\section{Approach for the Simulation of Reconfigurable Assembly Cells with Unity3D}

The proposed approach aims to decrease time and effort when introducing a new product variant into an existing assembly line. It simplifies the production planning process for new products on existing assembly systems. By simulating the process with Unity3D, it is determined if a new variant can be produced in the existing assembly cell configuration. Through modelling the existing flexibility ranges in the reconfigurable assembly cells they can also be automatically considered. If the current line configuration is not suitable for the new product, but the line can be reconfigured to allow production, proposals on how to change the configuration are automatically made to the production planer. For this purpose an approach for modelling flexibility ranges of assembly cells is developed. The flexibility ranges are defined automatically via calculations based on the possible cell configurations. Basis for the suitability evaluation is a detailed model of the processes that are to be performed. The process requirements are then compared with the cell's capabilities.

The proposed approach consists of seven steps, as shown in Figure 1. As preparation for the simulation, relevant data is obtained, processed and entered. The input for the simulation consists of constraints, predetermined tasks, the process, available resources and products. The proposed approach contains five preparation steps: task definition, CAD-Model preparation, cell assembly and product import, definition of the flexibility ranges and identification of product requirements. After the complete data import, the simulation can be started, and the comparison between requirements and cell capabilities and the derivation of solutions can be executed in the application. For the detection of possible collision errors or reachability problems in the examined process, a high level of detail has to be chosen to describe process and product.

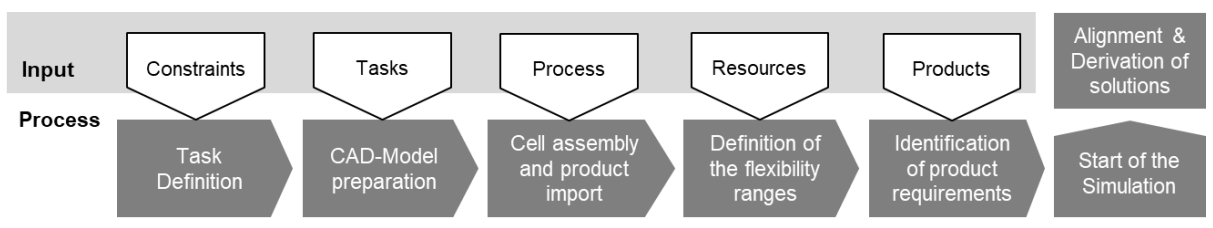

Fig. 1. Simulation procedure 


\subsection{Simulation Preparation}

First, the assembly task and the product requirements must be defined. Further relevant information are the characteristics of the current cell configuration. In order to achieve applicable results, the simulation model has to correspond to reality as closely as possible. Required data is therefore integrated by importing CAD-files of the cell into Unity3D. As Unity3D is not offering the possibility of importing those files directly, the models have to be converted to Unity3D format filmbox (.fbx). For this work, the CAD-program Autodesk 3DS Max was used. Further, the converted files are scaled to Unity3D standard, where one standard unit equals one meter. To be able to move the parts in the simulation relatively to each other the cell is rebuilt before the import in individual parts.

The product requirements must be identified before the start of the simulation. It is possible to load any product variant with differing requirements into the simulation. A program code automatically loads an object with default settings into a defined position in the simulation. First, it has to be determined how many and which process steps have to be carried out, what is required for the respective process step. Product requirements can be divided into direct and indirect. Direct requirements are defined by the dimensions of the product, number of machining steps, the resources required for the processes and the configuration of the needed equipment. Indirect requirements are independent of the product, like cycle times, quality standards and the use of certain components. Geometric dimensions are the only product feature that can be analyzed in Unity3D without additional information. Other parameters have to be inserted by the user and are stored in string variables to make them available for the comparison.

\subsection{Depiction of Reconfigurability in the Simulation}

To integrate flexibility, reconfigurability and modularity in the simulation model of the assembly cell the option in Unity3D to customize the program with C\# scripts is used. For this the total flexibility of a cell is divided into two levels, as shown in Figure 2.

\begin{tabular}{|l|}
\hline Flexibility-levell \\
\hline Cell configuration \\
- Determination of built-in, modular-assigned and installable equipment \\
- Number of possible process steps \\
$\qquad$\begin{tabular}{|l} 
Flexibility-level II \\
\hline Cell configuration \\
Different specifications and settings of the equipment
\end{tabular} \\
\hline
\end{tabular}

Fig. 2. Levels of flexibility in an assembly cell

The cell configuration provides the first flexibility range. This is done by determining whether equipment is built-in or modularly planned. For this purpose, the construction and processing areas, the process paths and the number of possible process steps in the cell are defined. At the equipment-level, flexibility is determined by the characteristics 
and settings of these. Together with the cell configuration, the equipment configuration determines the cell's solution space. The geometric representation of the equipment does not provide sufficient data for an informative simulation. The flexibility ranges are defined by specific queries and inputs. For individual process steps, it is defined which component is installed, if the concept is modular and retrofittable and if a new module has to be installed. This information is later used in the simulation process.

\subsection{Comparison of Product Requirements and Cell Capabilities}

In addition to geometric checks the parameters describing product requirements and cell skills are compared. The simulation can be used to examine if the components fit into the fixtures, if the machining areas are sufficient and if all processes can be executed without collisions. Entered parameters, information derived from the CAD-model and detected problems are stored automatically. In the next step it is checked whether the product requirements can be fulfilled within the defined flexibility ranges.

\subsection{Automatic Derivation of Possible Solutions}

The identified problems have to be converted in proposed solutions. Certain rules are defined for this purpose. The suggestions for solutions can be expressed product- or cell-related. In the present approach, changes can only be done to the cell, not to the product. The solution possibilities can be classified into three levels, as shown in Table 1. Category 1 includes modifications within the flexibility range [3]. According to industry needs, the two further classifications divide the solutions into whether the user or the cell-manufacturer has to make adjustments. Each individual process step is compared, the result categorized and the user is shown the necessary steps for the reconfiguration of the cell. Finally the option to rebuild of the cell according to the proposals is offered.

Table 1. Categorization of solution possibilities

\begin{tabular}{|l|l|}
\hline Category 1 & The assembly cell can adapt itself within the flexibility range. \\
\hline Category 2 & $\begin{array}{l}\text { The assembly cell user can implement new operating resources in } \\
\text { modular provided areas or change them. }\end{array}$ \\
\hline Category 3 & The assembly cell provider has to adjust the cell. \\
\hline
\end{tabular}

\section{$4 \quad$ Validation of the Approach}

The approach is evaluated based on an application case. The application example is the assembly of a surround view camera for vehicles at a large automotive supplier company. The selected process is dispensing, which is complex assembly process. In the process, glue is applied to the housing. The simulation is used to test which product requirements (e.g. connector geometries, dispensing-medium) necessitate a cell conversion. The simulation can run as an exported program without Unity3D. The program in Unity3D is structured in different scenes, representing different program windows. 
At the beginning of the simulation, the machining areas of the processes and the possible, previously defined process areas are displayed, as shown in Figure 3. These behave according to the inputs of the process paths and their geometric restrictions and are automatically adapted in the visual representation.

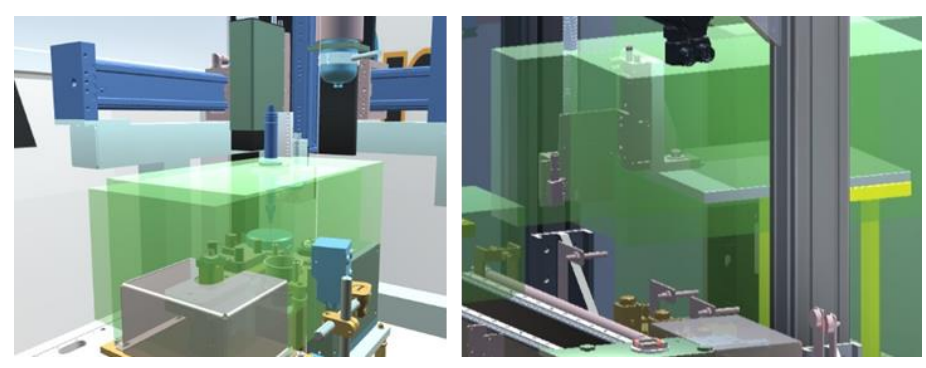

Fig. 3. Machining and process areas

The structure of the cell corresponds to the previously defined configuration. If the product requirements of the new variant are entered and the CAD-model has been successfully imported, the simulation can be started. The comparison starts in the simulation with accessibility studies and collision monitoring. The product is moved to the processing position with a shuttle axis and the glue is dispended according to the requirements. If post-treatments and security methods are selected, these are performed via the transfer system. After the comparison, the cell can be rebuilt according to the product requirements. This is done either within the flexibility ranges or by automatically adding further operating resources. The detection of a collision is displayed in Figure 4. The information is saved and serves as a basis for the comparison, which is largely parameter-based. The comparison takes place for each process and all parameters declared process-relevant. An output window is generated, showing the results and the possible solutions.

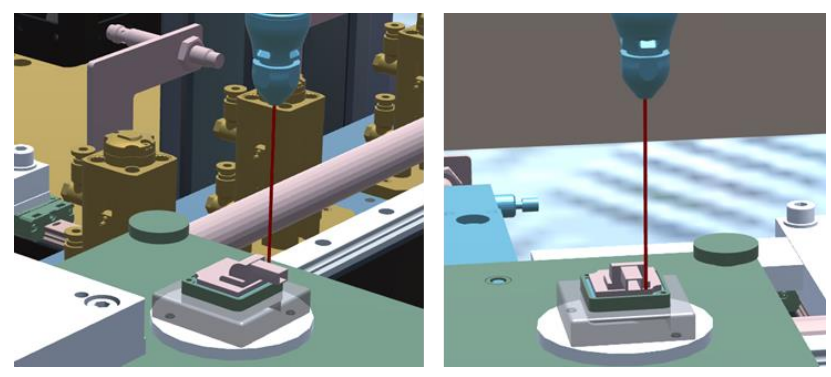

Fig. 4. Collision detection

The implementation in the application case allows the comparison of the skills of the current assembly cell to the requirements of two new and different variants in just one 
simulation. The created process transparency helps the company to quickly recognize necessary changes in the reconfigurable cell.

\section{$5 \quad$ Conclusion and Outlook}

The simulation of reconfigurable assembly cells enables an accelerated reaction to changing economic conditions. The development and introduction of the presented method can reduce planning efforts and support simultaneous engineering. In addition, the simulation enables the user to virtually validate the modularity of the manufacturing cell. The next step is to further evaluate the usability and quality of the results. Therefore, further different applications have to be tested. The input, data collection and the attachment of the requirements to the product has to be automated and simplified in further research.

\section{Acknowledgments}

The authors of this paper would like to thank the German Federal Ministry of Education and Research (BMBF) and the Project Management Agency Research Center Karlsruhe (PTKA) for funding this work, which is part of the research and development project ProMoA (funding number 02P15A100).

\section{$7 \quad$ References}

1. ElMaraghy, HA (2005) Int J Flex Manuf Syst 17: 261. doi:10.1007/s10696-006-9028-7

2. Koren Y, Heisel U, Jovane F, Moriwaki T, Pritschow G, Ulsoy G, Van Brussel H (1999) Reconfigurable Manufacturing Systems, Annals of the CIRP Vol. 48/2. doi:10.1016/S00078506(07)63232-6

3. Wiendahl H, ElMaraghy H, Nyhius P, Zäh MF, Wiendahl H-H, Duffie N, Brieke M (2007) Changeable Manufacturing - Classification, Design and Operation, Annals of the CIRP Vol. 56/.2 doi:10.1016/j.cirp.2007.10.003

4. Erdogan H (2019) Conti Temic microelectronic GmbH, Ringlerstr.17, Ingolstadt, Germany, Expert Interview 2019/03/25

5. Gyulai D, Pfeiffer A, Kadar B, Monostori L (2016) Simulation-based Production Planning and Execution Control for Reconfigurable Assembly Cells, Procedia CIRP, Volume 57. doi:10.1016/j.procir.2016.11.077

6. Khedri Liraviasl K, ElMaraghy H, Hanafy M, Samy SN (2015) A Framework for Modelling Reconfigurable Manufacturing Systems Using Hybridized Discrete-Event and Agent-based Simulation, IFAC-PapersOnLine, Volume 48, Issue 3. doi:10.1016/j.ifacol.2015.06.297

7. Deif AM, ElMaraghy HA (2011) A multiple performance analysis of market-capacity integration policies. Int J Manuf Res 6(3):191-214. doi:10.1504/IJMR.2011.041126

8. Unity3D-Multiplatform, https://unity3d.com/de/unity/multiplatform, last access 2019/02/27

9. Unity3D Homepage, https://unity3d.com/unity, last access 2019/02/27

10. Sun S, Hu L, Zheng L, Hu Y (2015) International Conference on Information and Automation: Design and simulation of the production line system based on multi-channel controller. IEEE, Lijang, China. doi:10.1109/ICInfA.2015.7279351 
11. Gaisbauer F, Agethen P, Otto M, Bär T, Sues J, Rukizo E (2018) CIRP: Presenting a Modular Framework for a Holistic Simulation of Manual Assembly Tasks, Vol.72, pp. 768-733. doi:10.1016/j.procir.2018.03.281

12. Um J, Fischer K, Spieldenner T, Kolberg D (2017) Procedia Manufacturing: Development a Modular Factory with Modular Software Components, Vol. 11, pp. 922-930. doi:10.1016/j.promf.2017.07.196

13. Gamlin A, Breedon P, Medjdoub B (2014) International Conference on Interactive Technologies and Games: Immersive Virtual Reality Deployment in a Lean Manufacturing Environment. IEEE, Nottingham, UK. doi:10.1109/iTAG.2014.13

14. Ouyang S, Wang G, Yao J, Zhu G, Liu Z, Feng C (2018) Computer Applications in Engineering Education, A Unity3D-based interactive three-dimensional virtual practice platform for chemical engineering, Vol. 26, pp. 91-100, John Wiley and Sons, New Jersey, US. doi:10.1002/cae.21863

15. Radionova LV, Chernyshev AD, Lisovskiy RA (2016) International conference on Industrial Engineering: Interactive Educational System- Virtual Simulator "Sheet Rolling", Procedia Engineering Volume 206, pp. 512-518. doi:0.1016/j.proeng.2017.10.509

16. Koechling D, Berssenbruegge J, Schluessler J, Stoecklein J (2016) Procedia Technology: Intelligent Production System Planning with Virtual Design Reviews, Vol. 206, pp.192-198. doi: 10.1016/j.protcy.2016.08.026 